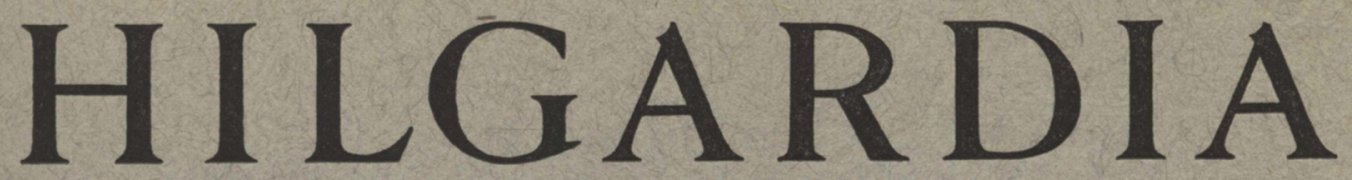

A Journal of Agricultural Science Published by the California Agricultural Experiment Station

\title{
AN EVALUATION OF NINE BACKCROSS-DERIVED WHEATS
}

COIT A. SUNESON 


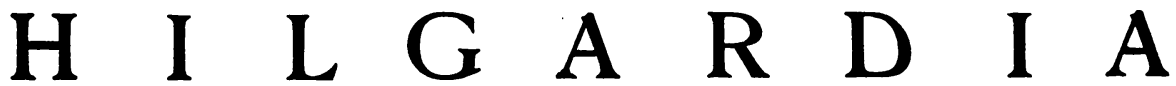

A Journal of Agricultural Science Published by

the California Agricultural Experiment Station

\section{AN EVALUATION OF NINE BACKCROSS-DERIVED WHEATS ${ }^{1}$}

\section{COIT A. SUNESON ${ }^{2}$}

ThE IMPRovement of established varieties of wheat through use of the backcross method of breeding was pioneered at the California Agricultural Experiment Station (Briggs, 1930). ${ }^{8}$ It seems advisable to present a new appraisal of the method that is based upon recent progress. For the plant breeder, the farmer, and the miller, the principal concern involves the degree of similarity, or difference, between a known commercial variety and its improved successor evolved by backcrossing where injury from diseases and insects does not occur. The results of numerous comparisons under such conditions are presented here. The procedures followed in the breeding of nine improved varieties and the genetic nature of these varieties are also discussed.

\section{REVIEW OF LITERATURE}

Theoretical assumptions regarding homozygosity of backcrossed populations and their similarity to their prototype varieties have been presented by Briggs $(1930,1938)$. These assumptions furnished the justification for the release of the improved varieties for commercial culture before extensive comparative performance data were available. Subsequently, a series of reports, each treating a successively larger body of data have been presented (Briggs, 1938; Suneson and Briggs, 1941; Suneson, Riddle, and Briggs, 1941; Riddle and Baker, 1944) emphasizing the similarity between the improved varieties and their prototypes. The improved varieties have been widely accepted by California farmers because of the economic advantage of the obvious improvements. In 1939, Baart and White Federation occupied 56 per cent of the California wheat acreage (Clark, 1942). In 1944, however, Baart 38 and White Federation 38, together with a very small residue of their prototypes, occupied approximately 70 per cent of the California wheat acreage, according to all available reports. This trend had been predicted (Suneson, 1945), but it was accelerated by state-wide rust damage in 1940 and 1941.

\footnotetext{
${ }^{1}$ Compiled from investigations of the Division of Cereal Crops and Diseases, Bureau of Plant Industry, Soils, and Agricultural Engineering, Agricultural Research Administration, U. S. Dept. of Agriculture; and the agricultural experiment stations of Arizona, California, Colorado, Idaho, Montana, Oregon, Washington, and Utah coöperating in a regional wheatimprovement program.

Agronomist and Regional Coördinator, United States Department of Agriculture, and Associate in Agronomy, University of California.

"See "Literature Cited" for citations, which are referred to in the text by author and date.
} 


\section{MATERIALS AND METHODS}

Since the results given in this paper are practical attempts to show the degree of return to the recurrent parental type in California backcross-derived varieties, special interest attaches to the pedigrees of the several improved varieties. The number of backcrosses and the size and management of the successive backcross generations are especially important. The pertinent facts are given below.

Big Club 37, C.I. No. 11901: Big Club 37 was derived from Martin backcrossed to Big Club six times (Martin $\times \mathrm{Big} \mathrm{Club}^{\tau}$ ). The first cross was made in 1922 and six backcrosses were added and successively tested for bunt, generally on $\mathrm{F}_{3}$ strains in alternate generations of backcrossing, until 1936, when 77 homozygous bunt-resistant $\mathrm{F}_{3}$ lines were bulked to make the variety.

Sonora 37, C.I. 11902 (Martin $\times$ Sonora ${ }^{7}$ ) : Sonora 37 was produced in the same way and at the same time, $71 \mathrm{~F}_{3}$ lines being bulked.

Pacific Bluestem 37, C.I. 11903 (Martin $\times$ Pacific Bluestem ${ }^{7}$ ): This variety, also produced at the same time and in the same way, consists of a composite of $78 \mathrm{~F}_{3}$ lines.

White Federation 38, C.I. 11906 (Hope-White Federation ${ }^{5} \times$ Martin-White $^{-}$ Federation ${ }^{6}$ ) : Martin smut resistance and Hope stem-rust resistance carried through independent backcrossing programs and then merged in a final cross from which 182 doubly resistant $\mathrm{F}_{3}$ lines were bulked in 1937 .

Baart 38, C.I. 11907 (Hope-Baart ${ }^{5} \times$ Martin-Baart $^{7}$ ) : This variety was produced in the same way and at the same time as White Federation 38, except that $157 \mathrm{~F}_{3}$ lines were bulked.

Onas 41, C.I. 12,229 (Martin-White Federation ${ }^{8} \times$ Onas $^{8}$ ): Onas 41 is a composite of 115 homozygous bunt-resistant $\mathrm{F}_{3}$ lines.

Federation 41, C.I. 12,230 (Martin-White Federation ${ }^{8} \times$ Federation $^{6}$ ) : Federation 41 was produced concurrently with Onas 41 from a composite of $130 \mathrm{~F}_{3}$ lines.

Poso 42, C.I. 12,237 (Dawson $\times \mathrm{Poso}^{\circ}$ ) : This Hessian-fly-resistant variety is a composite of $45 \mathrm{~F}_{4}$ lines.

Big Club 43, C. I. 12,244: This variety is a composite of 144 triply resistant (bunt, Hessian fly, and stem rust) $\mathrm{F}_{3}$ lines. It resulted from three independent breeding programs :

(1) Production of Big Club 37 as noted above.

(2) Dawson-Big Club $\times$ Big Club $37^{2}$.

(3) Hope-Baart $\times$ Big Club $^{2} \times$ Big Club $37^{2}$.

The final merger involved random crossing of (2) on (3), and then of (2) on the $\mathrm{F}_{1}$ of these.

Comparisons herein reported are drawn from plot or nursery tests in which the commercial variety and the improved strain were grown in paired tests, where stem rust, bunt, or Hessian fly was not reported as a differentiating yield factor. Most of the data were compiled from results at 18 experiment stations coöperating in the western regional wheat-improvement program (Suneson, Riddle, and Briggs, 1941). Other data came from coöperative tests on farms in California and Nevada. Yield data are reported for individual plots, while other data, such as height, heading date, test weight, and lodging 
are reported only as an average for the several replicates (either an average of independent measurements, or a single measurement on a composite sample). All available data on each item are included.

TABLE 1

Comparative Yields of BaArt and BaArt 38 at Western Experiment Stations and in California and Nevada Farm Tests, 1939-1944*

\begin{tabular}{|c|c|c|c|c|c|c|}
\hline \multirow{3}{*}{ Station } & \multicolumn{2}{|c|}{ Mean yields per acre } & \multirow{3}{*}{$\begin{array}{c}\text { Yield } \\
\text { differences }\end{array}$} & \multicolumn{3}{|c|}{ Binomial yield distributions } \\
\hline & \multirow{2}{*}{ Baart } & \multirow{2}{*}{ Baart 38} & & \multicolumn{2}{|c|}{$\begin{array}{l}\text { Number of times } \\
\text { superior }\end{array}$} & \multirow{2}{*}{$\begin{array}{c}\text { Number } \\
\text { of ties }\end{array}$} \\
\hline & & & & Baart & Baart 38 & \\
\hline 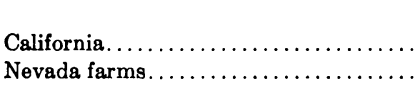 & $\begin{array}{c}\text { bushels } \\
35.9 \\
29.1\end{array}$ & $\begin{array}{c}\text { bushels } \\
36.6 \\
29.9\end{array}$ & $\begin{array}{c}\text { bushels } \\
+0.7 \\
+0.8\end{array}$ & $\begin{array}{r}31 \\
5\end{array}$ & $\begin{array}{r}32 \\
4\end{array}$ & $\begin{array}{l}4 \\
0\end{array}$ \\
\hline Mesa, Ariz........................ & 38.8 & 39.3 & +0.5 & 4 & 6 & 0 \\
\hline Sacaton, Ariz....................... & 30.6 & 31.0 & +0.4 & 1 & 2 & 0 \\
\hline Hesperus, Colo..................... & 44.8 & 42.0 & -2.8 & 3 & 2 & 1 \\
\hline Pendleton, Ore... & 37.4 & 35.8 & -1.6 & 11 & 7 & 0 \\
\hline Moro, Ore........................ & 26.4 & 26.7 & +0.3 & 16 & 14 & 0 \\
\hline Union, Ore.......................... & 54.2 & 55.3 & +1.1 & 7 & 4 & 0 \\
\hline Pullman, Wash................... & 52.1 & 52.8 & +0.7 & 9 & 13 & 2 \\
\hline Prosser, Wash..................... & 49.9 & 48.4 & -1.5 & 7 & 4 & 1 \\
\hline Lind, Wash....................... & 25.1 & 25.3 & +0.2 & 7 & 10 & 1 \\
\hline Pomeroy, Wash.................... & 28.0 & 28.4 & +0.4 & 5 & 4 & 2 \\
\hline Walla Walla, Wash.................. & 38.3 & 38.4 & +0.1 & 9 & 9 & $\mathbf{0}$ \\
\hline Moscow, Idaho................... & 37.2 & 36.6 & -0.6 & 6 & 12 & 0 \\
\hline Sandpoint, Idaho.................. & 24.8 & 24.6 & -0.2 & 2 & 3 & 0 \\
\hline Tetonia, Idaho.................. & 28.4 & 25.1 & $-3.3 \dagger$ & 16 & 6 & $\mathbf{0}$ \\
\hline Aberdeen, Idaho...................... & 68.4 & 68.6 & +0.2 & 12 & 8 & 0 \\
\hline Bozeman, Mont.............. & 58.6 & 57.3 & -1.3 & 9 & 5 & 0 \\
\hline 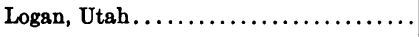 & 54.2 & 54.9 & +0.7 & 7 & 6 & 0 \\
\hline All tests.................... & 39.59 & 39.45 & -0.14 & 167 & 151 & 11 \\
\hline
\end{tabular}

- This summarizes all coöperative plot and nursery tests reported to the author excluding only nonpaired tests, or tests wherein stem rust affected yields. The California tests include tests on farms in coopperation with the Agricultura! Extension Service.

† Odds are greater than 19:1 that this difference is not due to chance.

Mean differences, supported by odds determined from the point binomial distributions (Miles, 1935) are used to determine the similarity between the commercial and the improved strain. This method of statistical analysis is conservative and is particularly useful in studies of this kind because of its ease of application.

\section{RESULTS}

Agronomic Evaluation. Since Baart was the most widely grown variety in the western region (Clark, 1942) and Baart 38 has now almost completely replaced it in California, Arizona, and Nevada and is being grown in Oregon, 
Idaho, and Utah, it is logical that the most extensive comparisons involve these two varieties. Detailed data on yield from all available sources in the region are presented in table 1. These represent tests from 1939 through 1944, excluding only nonpaired tests or comparisons in which stem rust was a differentiating yield factor. For the six-year period, 59 tests were excluded because of the presence of stem rust. Mean yields of the two varieties at all locations and the number of times when each was superior are shown. From this it can be deduced that only at Tetonia, Idaho, has a significant difference (at the 5 per cent level) between the two varieties been found. In this case the results favored Baart.

TABLE 2

Differences in Agronomic Characteristics Between BaArt and Baart 38, Western Regional Tests*

\begin{tabular}{|c|c|c|c|c|c|c|c|c|}
\hline \multirow{2}{*}{ Year } & \multicolumn{2}{|c|}{$\begin{array}{c}\text { Date headed } \\
\text { (April } 16 \text { to July 22) }\end{array}$} & \multicolumn{2}{|c|}{$\begin{array}{l}\text { Plant height } \\
\text { (25 to } 68 \text { inches) }\end{array}$} & \multicolumn{2}{|c|}{$\begin{array}{c}\text { Lodging } \\
\text { (0 to } 25 \text { per cent) }\end{array}$} & \multicolumn{2}{|c|}{$\begin{array}{l}\text { Weight per bushel } \\
\text { (53.9 to } 66.5 \text { pounds) }\end{array}$} \\
\hline & $\begin{array}{l}\text { Number } \\
\text { of tests }\end{array}$ & $\begin{array}{c}\text { Mean } \\
\text { difference }\end{array}$ & $\begin{array}{l}\text { Number } \\
\text { of tests }\end{array}$ & $\begin{array}{c}\text { Mean } \\
\text { difference }\end{array}$ & $\begin{array}{c}\text { Number } \\
\text { of tests }\end{array}$ & $\begin{array}{c}\text { Mean } \\
\text { difference }\end{array}$ & $\begin{array}{c}\text { Number } \\
\text { of tests }\end{array}$ & $\underset{\text { difference }}{\text { Mean }}$ \\
\hline & & days & & inches & & per cent & & pounds \\
\hline $1939 \ldots \ldots \ldots \ldots \ldots \ldots \ldots$ & 11 & -0.1 & 11 & -0.3 & 2 & -9 & 13 & +0.1 \\
\hline $1940 \ldots \ldots$ & 10 & +0.2 & 12 & -0.3 & 6 & +1 & 11 & +0.3 \\
\hline $1941 \ldots \ldots$ & 13 & -0.8 & 12 & -0.1 & 3 & -2 & 4 & +0.3 \\
\hline n........... & 11 & 0.0 & 12 & -1.0 & 4 & -6 & 12 & +0.6 \\
\hline $1943 \ldots \ldots \ldots \ldots \ldots \ldots \ldots$ & 10 & +0.3 & 11 & 0.0 & 4 & +5 & 11 & +0.4 \\
\hline $1944 \ldots \ldots \ldots \ldots \ldots \ldots \ldots$ & 10 & +0.3 & 12 & -0.5 & $\mathbf{5}$ & -9 & 12 & +0.3 \\
\hline Total or mean.. & 65 & -0.05 & 70 & -0.36 & 24 & -2.8 & 63 & +0.33 \\
\hline
\end{tabular}

* Exclusive of environments known to be favorable to the improved variety.

As an average of all 329 plot comparisons, no significant difference was found despite the wide range of environments in which the tests were conducted. This means that although Baart outyielded Baart 38 by an average of 0.14 bushel, there is little likelihood that there is any real difference between these two varieties.

Comparative agronomic data for Baart and Baart 38 are presented in table 2. It has been mentioned that the unit data treated here are available only as averages of all plots at each station. The fact that some stations have equipment for determining test weights that is calibrated in half-pound intervals, while others show 0.1 pound difference is also worthy of note. Nevertheless, the preponderance of individual instances in which Baart 38 was shorter and weighed more per bushel than Baart suggests that the small average differences reported are probably significant. The differences in height and in test weight were 0.36 inch and 0.33 pound per bushel, respectively. While Baart 38 showed a range of from 2 days earlier to 5 days later than Baart, its average heading date was the same as for Baart. Other differentiating agronomic comparisons failed to show significant differences between the two varieties. These comparisons are not shown in table 2 , but such factors as shattering and susceptibility to mildew, septoria, stripe rust, and root rot are included. 
In establishing some slight, but apparently significant differences between the two varieties, it must be remembered that they are nevertheless substantially alike-so much so that large populations and diverse environments must be sampled to establish the slight differences herein reported.

Apart from emphasizing similarities between Baart and Baart 38, it also seems desirable to call attention to the economic advantage resulting from the commercial distribution of Baart 38. Its resistance to certain races of bunt and stem rust is unquestioned. Comparative tests in the presence of bunt have not been conducted, but a fairly representative body of data from stem-rust environments is available. Of the 59 tests excluded from table 1, 23 were

TABLE 3

Differential Annual Development of Stem Rust on BaArt and on BaArt 38 at Davis, WITH RELATED YIELd AND TEST-WEIGHT DATA

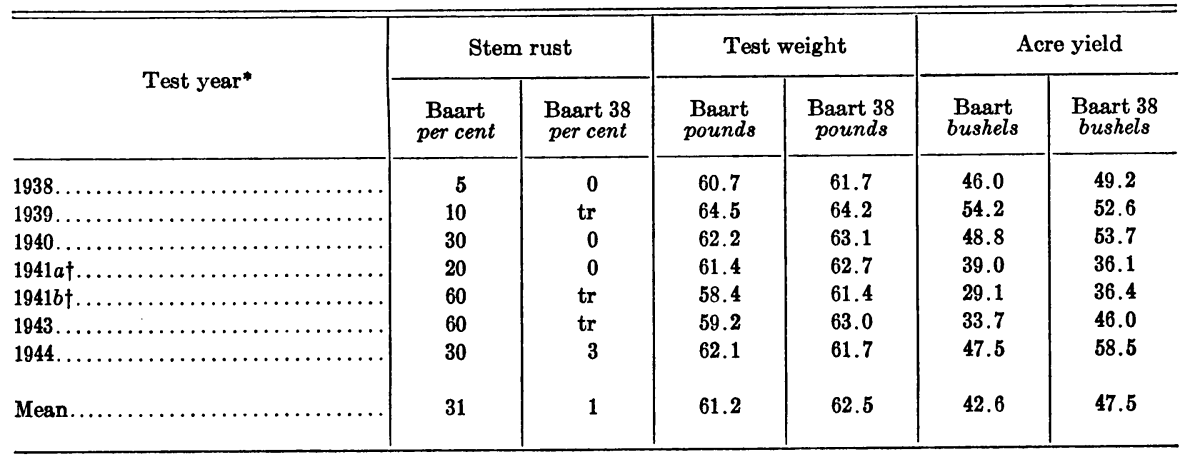

* No stem rust developed in the 1942 tests.

$\dagger 1941 a$, seeded November 26, 1940; 1941b, seeded January 31, 1941.

in California and cover all years from 1938 to 1944 except 1942. None of these involved a susceptible stem-rust reaction in Baart 38, nor an extremely high incidence of stem rust in Baart. Nevertheless, the average of these California tests, in which there was 31 per cent of rust-damaged tissue in Baart and only 1 per cent in Baart 38, produced an average difference of 1.3 pounds in test weight and 5 bushels in yield, as shown in table 3. Although not all of the area in which Baart is grown in California is subject to as frequent or as severe an incidence of rust as was experienced at Davis from 1938 to 1944, some areas are far more vulnerable. Also the state-wide severe losses of 1940 and 1941 must not be overlooked. It is safe to assume an average annual yield advantage of 10 per cent for one fourth of the 160,000 acres of Baart 38 that is now being grown. Since rust is more common on fertile lands, the average yield of Baart is about 40 bushels per acre. On this basis, the release of Baart 38 has added 160,000 bushels annually to California's wheat production. This is accomplished without any change in wheat acreage or change in the basic varietal type. Furthermore, Baart 38 tests on the average 1.3 pounds more per bushel where rust occurs and also tests slightly more than Baart in other sections-an advantage to the miller. Similar annual yield increases and production security followed the release of White Federation 38, which also is grown on approximately 160,000 acres in California. 
For the region as a whole, the occurrence of rust was less frequent than in California. In a few instances rust races appeared to which Baart 38 is nearly as susceptible as is Baart. Nevertheless, an average of all the 59 tests in which rust injury was recorded showed a bushel weight difference of 1.3 pounds, and a yield difference of 3.5 bushels in favor of Baart 38.

Eight other backcross-derived varieties have been compared with their commercial prototypes in 13 or more tests in which their resistance to rust, bunt, or Hessian-fly injury was of no advantage. These data are summarized in table 4. Four of these varieties were grown in additional states, but Sonora 37, Big Club 37, Poso 42, and Big Club 43 were tested only in California.

TABLE 4

Comparison of Yields and Their Underlying Binomial Distributions for Basic and BaCKCROSS-IMPROVEd STOCKS OF WhFat VARIETIES IN WESTERN Regional Tests*

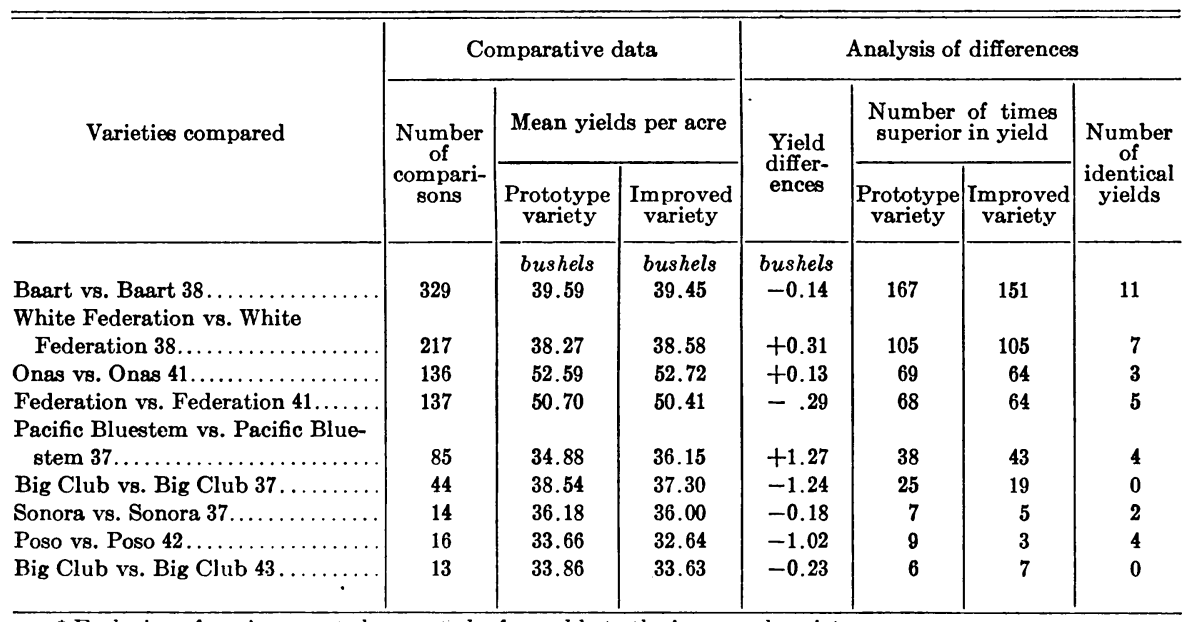

* Exclusive of environments known to be favorable to the improved variety.

In no case has a significant mean yield difference between à commercial variety and its backcross-derived successor been established. Nonsignificant differences are either positive or negative, according to the variety comparison involved. Hence, it must be concluded that all pairs are substantially alike in their aggregate yield performance over a wide diversity of environments. The data were compiled by individual stations but regional averages only are reported here. At only one station-Aberdeen, Idaho-does the difference in yield appear to be significant. Federation, with an average yield of 82 bushels, exceeded Federation 41 by 4.4 bushels, being superior in 11 of the $13 \mathrm{com}$ parisons. With this exception none of the differences in agronomic data appear to be significant.

Quality. Each season certain varieties under test in the western region are subjected to milling, baking, and other physical and chemical tests (Fifield, et al., 1941). The averages of all such tests with experiment-station samples of the four principal variety pairs grown during the years 1938 to 1943 are shown in table 5 . Some modifications in analytical procedure and baking formulas have occurred during the experiments, but for purposes of gross evaluation these have been disregarded in computing averages. 


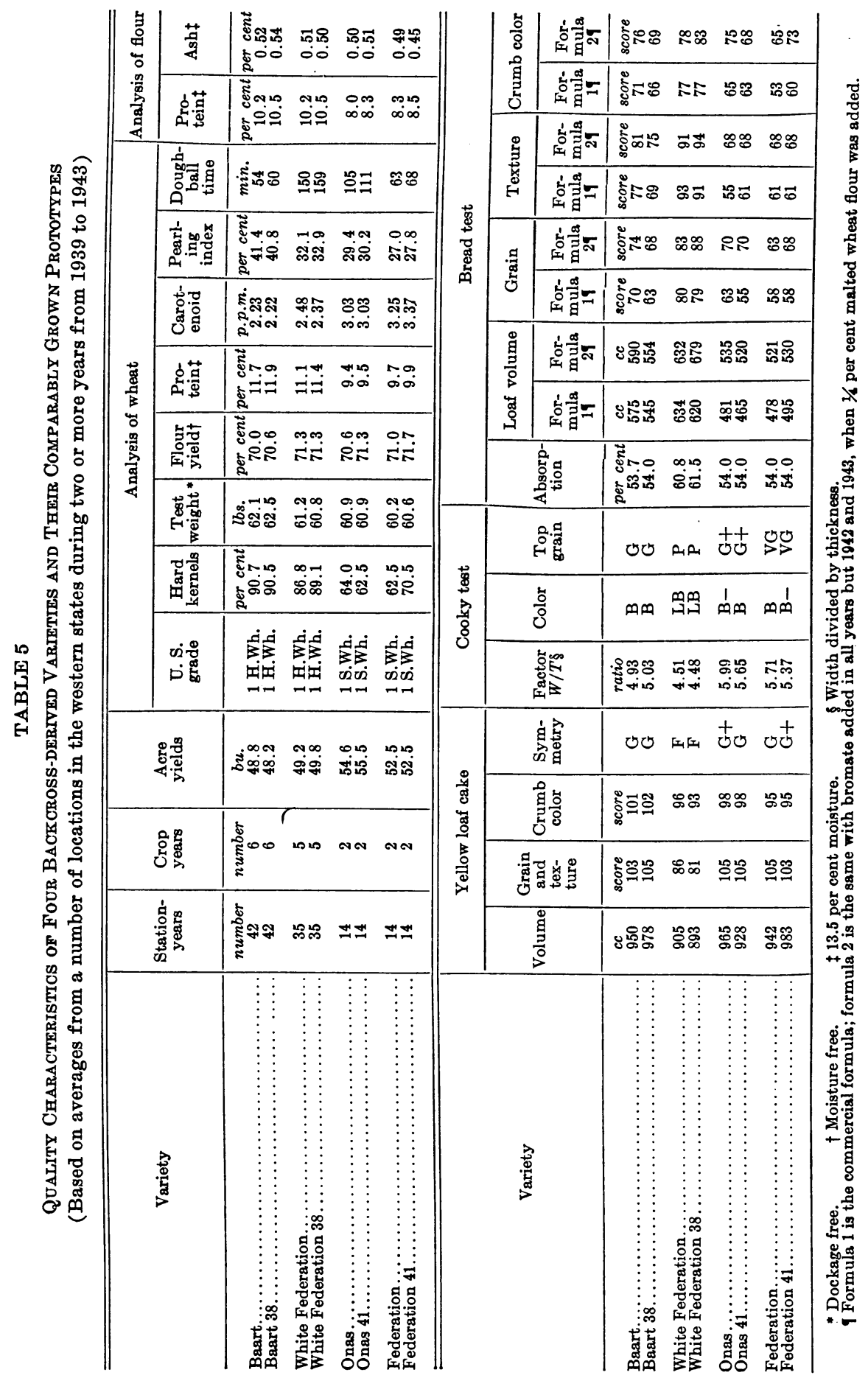


The greatest number of tests were with Baart and Baart 38, and the greatest differences also were found between these paired varieties. Perhaps the most significant difference between Baart and Baart 38 is in their bread-making properties. Baart 38 has rather consistently produced lower loaf volumes, and grain, texture, and crumb-color values. These differences are small, but nevertheless appear to be significant, especially when considered in relation to the slightly higher protein content in Baart 38 . Thus while it is not improbable that some other formula for making bread might make as good bread from Baart 38 as any shown here for Baart, Baart 38 apparently must be admitted to have slightly different quality attributes from Baart. This is further evidenced by the slight superiority of yellow loaf cake and of cookies baked from Baart 38. Other quality differences between Baart and Baart 38 shown in table 5 probably are not real. Many of the tests suggest close similarity rather than any difference between Baart and Baart 38.

Quality averages for three other backcross-derived varieties and their prototypes also are reported in table 5. For these, and for three other derivatives tested for only 1 year-Pacific Bluestem 37, Big Club 37, and Sonora 37-the data suggest general similarity in quality to their comparably grown prototypes. If some of the small differences are real, further testing will be necessary to establish the reality. In any case a fairly close approximation of the physical and chemical, as well as the baking responses of the prototype varieties obviously has been obtained by the backcross method of breeding as practiced in California.

\section{DISCUSSION}

From the data presented, critics of the backcross method can readily point to differences, and supporters even more readily to similarities. As the person who has been privileged to observe and study the performance of these varieties most extensively and intensively, the writer has sought to give this new breeding method a strictly objective evaluation.

In paired plantings, even a skilled agronomist usually cannot detect any morphological differences between the backcross-derived varieties and their prototypes, much less distinguish them. In rare instances, both can be done, usually by the manifestation of greater variability within the backcrossderived population. In this connection, it is important to recall that all of these varieties resulted from the making of a rather large number of crosses in each backcross generation and finally merging many $F_{3}$ or $F_{4}$ lines. It is this bulking of lines which probably accounts for the aggregate performance being so like that of the commercial variety under all environments, and yet makes possible minor aggregate differences in yield, test weight, plant height, and quality. That these or any other undetermined aggregate differences are more than minor differences certainly does not seem likely from the data at hand. Thus, there is justification for use of the common name, and general substitution of the backcross-improved stock wherever its imparted resistance is useful.

The variability occurring in the improved variety is both useful and dangerous. If a nonrecurrent parent in the pedigree of a backcross-derived variety possesses some desirable trait that has not been eliminated through conscious 
selection, it can probably be recovered by extensive selection. The recent recovery of selections of Baart 38 with purple straw, light red seeds, and striperust resistance, are indicative of the possibilities, as are the selections from Federation 41 that are superior in winter hardiness or mildew resistance.

The diversity occurring is desirable when a variety is being improved by a succession of backcrosses with different varieties. Independent advanced breeding programs underway in California anticipate production of: (1) awnless; (2) short-strawed; (3) early-maturing; and (4) bronze-glumed forms of Baart that are resistant to both smut and stem rust. Two further backcrosses to Baart recently have been made partly to utilize the maximum level of stem-rust resistance extant in Baart 38, but more especially to minimize the genetic diversity from Baart. This stock, to be known as Baart 46 , may never be grown commercially but it will be used as the recurrent parent instead of Baart in concluding backcrosses for the production of the new types mentioned above and for other future crossing. Thus, while only five or six backcrosses were necessary to achieve the high similarities reported herein, two or more additional backcrosses seem desirable when more than three improvements are to be consolidated into one improved variety.

\section{SUMMARY}

The average yields of nine backcross-derived varieties grown in paired comparisons with their commercial prototypes in tests in nine western states failed to show any general significant differences in yield between the paired strains when disease and insect injury were absent or the same for both strains.

However, significant differences in yield were evident at two stations. At Tetonia, Idaho, there was an 11 per cent yield advantage for Baart as compared with Baart 38 and at Aberdeen, Idaho, Federation showed a 5 per cent advantage over Federation 41.

From an average of more than 60 tests, Baart 38 excelled in test weight by 0.33 pound and was 0.36 inch shorter than Baart. Though these differences have a high mathematical probability of being real, they represent differences of only 0.6 and 0.9 per cent, respectively. Baart 38 was inferior to Baart in bread-making quality.

All of the data emphasize the high degree of similarity between varieties and their progenies produced from five or more backcrosses. Substitution for existing commercial varieties of any of the improved varieties herein considered, or of any subsequently produced by similar successful breeding methods, seems desirable wherever the effected improvements will operate to minimize production losses. Except for the specified improvements, the general performance of the improved varieties has been indistinguishable from those of the progenitor varieties. 


\section{LITERATURE CITED}

BrigGs, Fred N.

1930. Breeding wheats resistant to bunt by the backcross method. Amer. Soc. Agron. Jour. 22:239-44.

1938. The use of the backeross in crop improvement. Amer. Nat. 72:285-92.

Clark, J. A., and K. S. QUISENBERRY.

1942. Distribution of the varieties and classes of wheat in the United States in 1939. U. S. Dept. Agr. Cir. 634:1-75.

Fifield, C. C., H. C. Fellows, Ray Weaver, J. F. Hayes, Elwood Homfecker, and B. E. ROTHBEG.

1941. Quality studies of wheat varieties grown in the western region in 1939. U. S. Bur. Plant Indus., Div. Cereal Crops and Dis. 63 p. (Mimeo.)

MILES, S. R.

1935. A very rapid and easy method of testing the reliability of an average and a discussion of the normal and binomial methods. Amer. Soc. Agron. Jour. 27:21-31.

RIDDLE, O. C., and G. A. BAKER.

1944. Biases encountered in large-scale yield tests. Hilgardia 16(1):1-14.

SunEson, C. A.

1945. Results from coöperative wheat varietal experiments in the western region in 1944, with averages for 1941 to 1944. U. S. Bureau of Plant Industry, Soils, and Agr. Engin., Div. Cereal Crops and Dis. Mimeo. Release, 22 CC:1-22. Davis, Calif.

SUNESON, C. A., and F. N. BRIGGS.

1941. Wheat production in California. California Agr. Exp. Sta. Bul. 659:1-18.

Suneson, C. A., O. C. Ridple, and F. N. Briggs.

1941. Yields of varieties of wheat derived by backcrossing. Amer. Soc. Agron. Jour. 33: 835-40. 
